\title{
HIGH GAIN RECTANGULAR MICROSTRIP PATCH ANTENNA EMPLOYING POLYSTYRENE SUBSTRATE FOR SATELLITE COMMUNICATION APPLICATIONS
}

\author{
Jaspreet Singh ${ }^{1}$, Gurnoor Singh Brar ${ }^{2}$, Ekambir Sidhu ${ }^{3}$ \\ ${ }^{1}$ Student, Department of Electronics and Communication Engineering, Punjabi University Patiala, India \\ ${ }^{2}$ Student, Department of Electronics and Communication Engineering, Thapar Polytechnic College, Patiala, India \\ ${ }^{3}$ Assistant Professor, Department of Electronics and Communication Engineering, Punjabi University, Patiala, India
}

\begin{abstract}
The paper presents a rectangular microstrip patch antenna design suitable to be employed for fixed satellite (Space to Earth)communication and defence systems. The Polystyrene substrate has been used with dielectric constant $\left(\epsilon_{r}\right)$ of 2.6 having thickness of $2 \mathrm{~mm}$. The material used for patch, feed line and ground is perfect electric conductor (PEC). The ground surface has been reduced in order to enhance the performance in terms of bandwidth and return loss. The feed line of suitable width has been employed for matching the impedance of antenna $(50 \mathrm{ohm})$ with port impedance for maximum power propagates from port to antenna with minimal reflection losses. The prototype antennaresonates at frequency of $4.4 \mathrm{GHz}$ with operating frequency range of $4.18 \mathrm{GHz}$ to $6.61 \mathrm{GHz}(2.431 \mathrm{GHz}$ impedance bandwidth) and corresponding return loss of -36.3dB. The antenna has gain and directivity of $7.523 \mathrm{~dB}$ and directivity of $7.325 \mathrm{dBi}$, respectively. The performance of antenna has been analyzed in terms of return loss $(d B)$, gain $(d B)$, directivity $(d B i)$, smith chart and VSWR. The proposed antenna has been designed and simulated using CST Microwave studio 2014.
\end{abstract}

Keywords:- $d B, d B i$, Defence Systems, Directivity, Fixed Satellite Communication, Gain, Rectangular Microstrip Patch, Return Loss

\section{INTRODUCTION}

Nowadays, the communication systems are becoming compact in size and the compact antenna with enhanced performance are required for modern communication systems. The microstrip patch antenna is best suitable for these type of communication systems if the bandwidth performance is improved [1][2][3]. The microstrip patch antenna is usually fabricated on a dielectric material which acts as an intermediate between ground surface and radiating patch [4]. Antenna size basically depends on the dielectric constant of the substrate. Higher is the value of dielectric constant, lower is the size of the antenna [5]. Microstrip patch antenna's bandwidth can be improved either by having slot on patch [6][7] or a reducing ground [8][9]. By using these techniques the return loss along with bandwidth enhancement can also be improved. There are various methods of feeding antenna such as proximity coupled microstrip feed, coaxial feed and aperture coupled microstrip feed [10]. Different type of shapes of slot have different effect on different parameters of antenna. By having different slots one can improve the antenna performance in terms of bandwidth, return loss and VSWR [11][12].

Nowadays, for wireless applications commonly Microstrip patch antenna are employed because of its low cost, light weight, miniaturization, ease of mobility, ease of fabrication and better efficiency. However, the microstrip patch antenna suffers from drawbacks also such as it has limited bandwidth and it handles less power[12][13].

\section{ANTENNA DESIGN}

The Fig. 1, Fig. 2 and Fig. 3 illustrate the dimensions of the propounded Microstrip patch antenna. In the given antenna design, substrate of thickness $2 \mathrm{~mm}$ has been used. The substrate is of polystyrene material having dielectric constant of 2.6. The arrangement of substrate, patch and ground are shown in Fig. 1. 


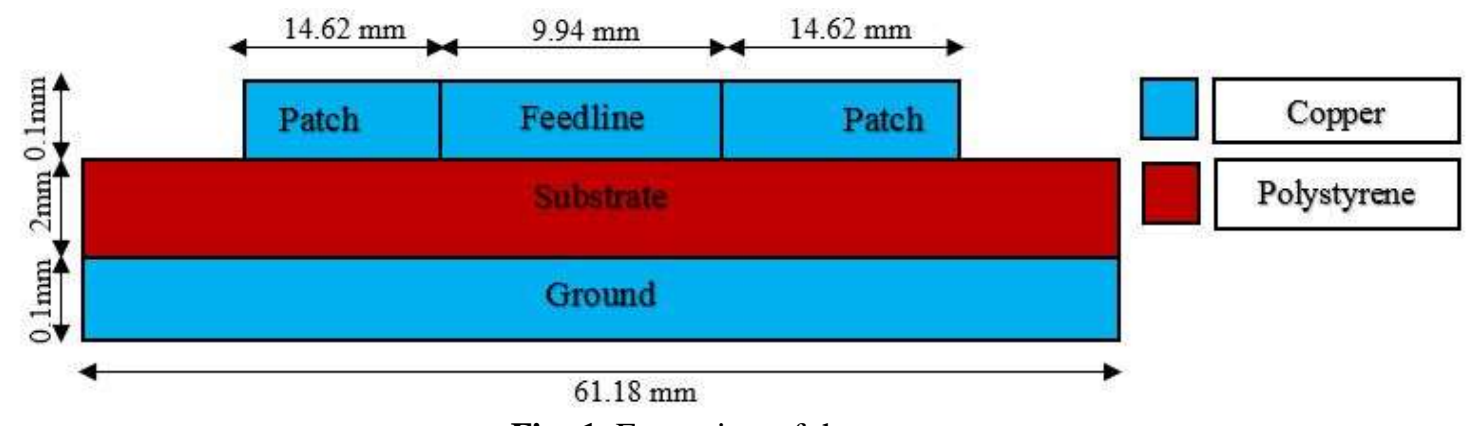

Fig -1: Front view of the antenna
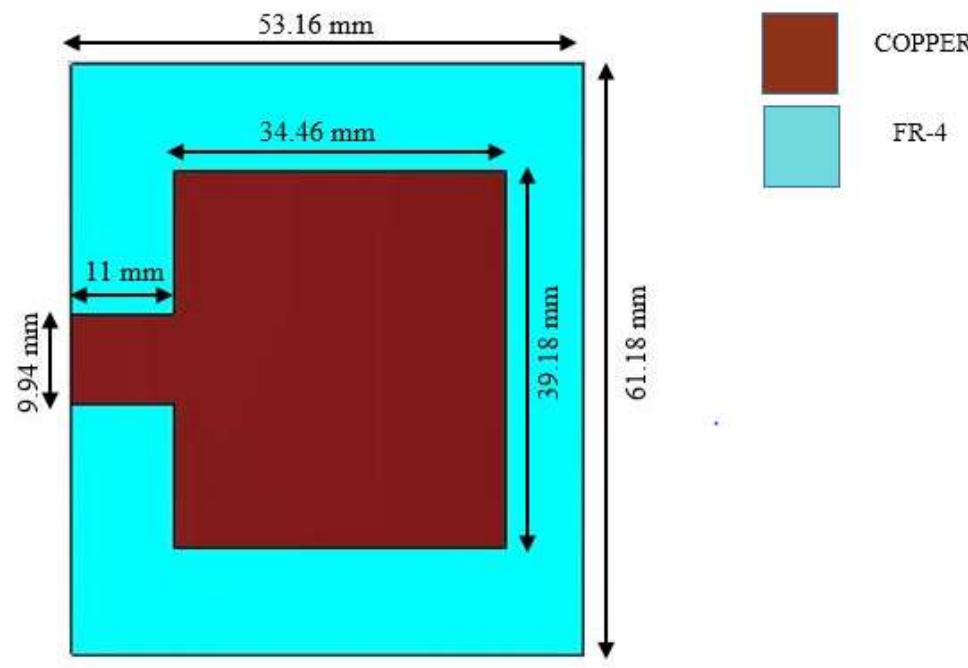

FR-4

Fig -2: Top view of the antenna
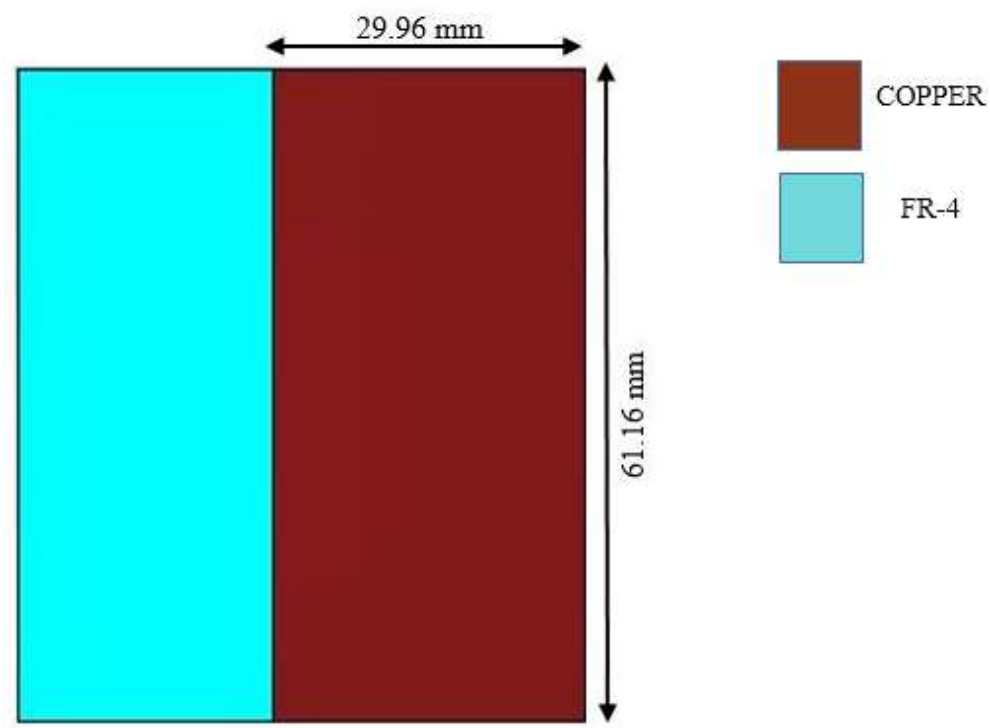

Fig -3: Bottom view of the antenna

\section{RESULTS}

The CST Microwave Studio 2014 has been used to design the proposed antenna design. The performance of the proposed High gain rectangular microstrip patch antenna has been analyzed in terms of return loss $(\mathrm{dB})$, resonant frequency $(\mathrm{GHz})$, directivity $(\mathrm{dBi})$, gain $(\mathrm{dB})$, impedance bandwidth $(\mathrm{GHz})$, VSWR and impedance (ohms). The return loss plot illustrates that the antenna is resonant at 4.4 $\mathrm{GHz}$ with a return loss of $-36.30 \mathrm{~dB}$ which has been shown in fig. 4.The smith chart of the proposed antenna is shown in fig. 5 which indicates that the proposed antenna has impedance of $50.16 \Omega$. The respective gain and directivity at $4.4 \mathrm{GHz}$ is found to be $7.523 \mathrm{~dB}$ and $7.325 \mathrm{dBi}$ as shown in Fig. 6. and Fig. 7. The VSWR(Voltage standing wave ratio) plot of the antenna has been shown in Fig. 8 which implies that the VSWR of the proposed antenna design lies below the minimum acceptable value of 2 . Fig. 9 shows the radiation pattern of the proposed antenna. 


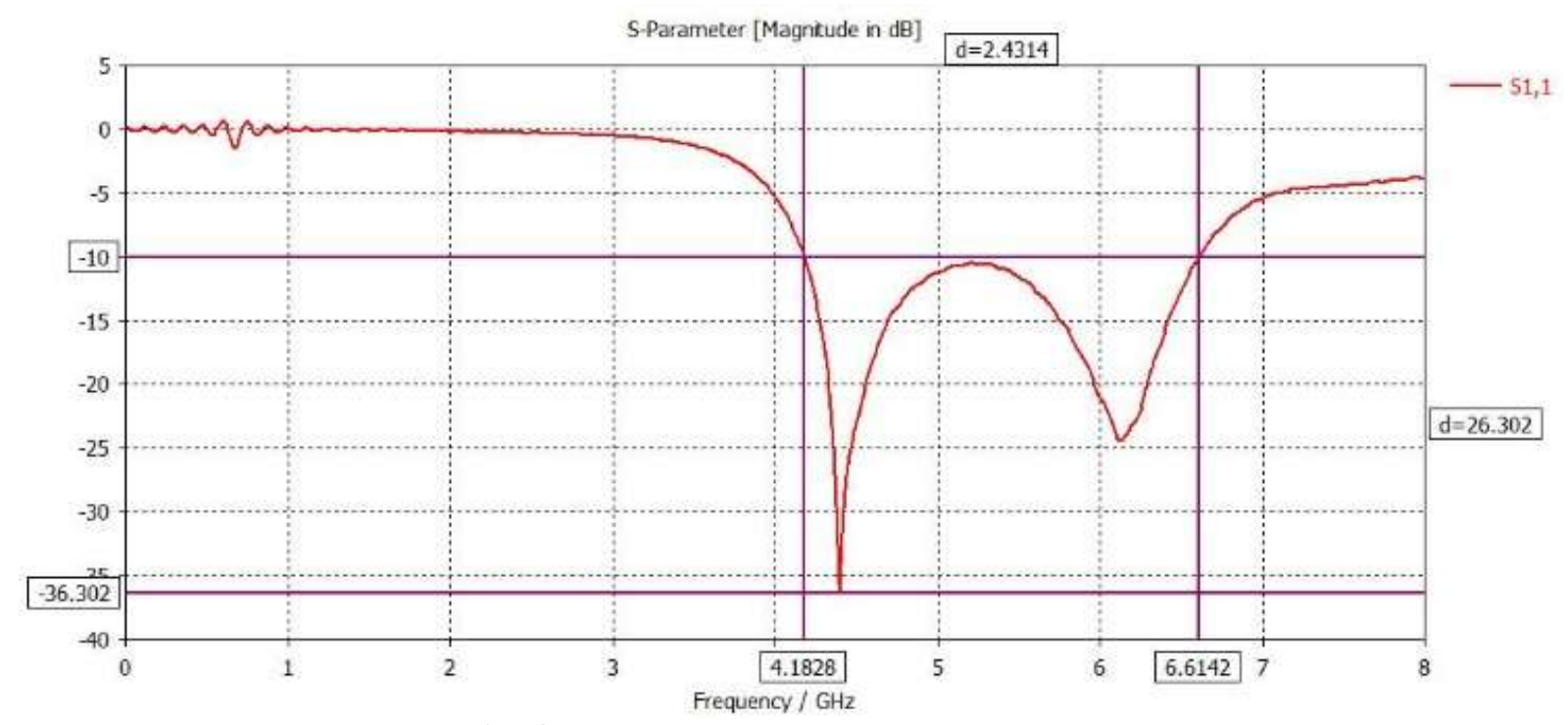

Fig -4: Return loss plot of the proposed antenna

$00(-0.477,2.19 \mathrm{e}-006)$ Ohm

- $8(11,5.37) \mathrm{Ohm}$

Frequency / $\mathrm{GHz}$

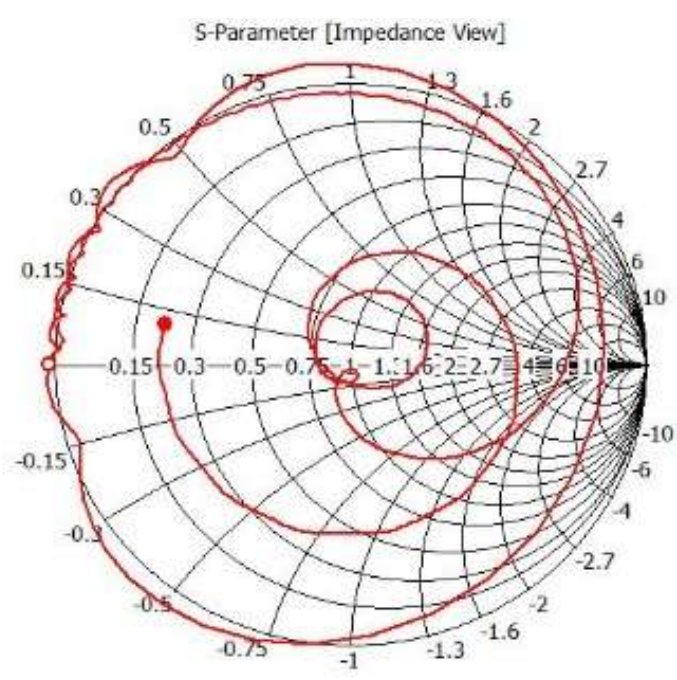

Fig -5: Smith Chart plot of the proposed antenna

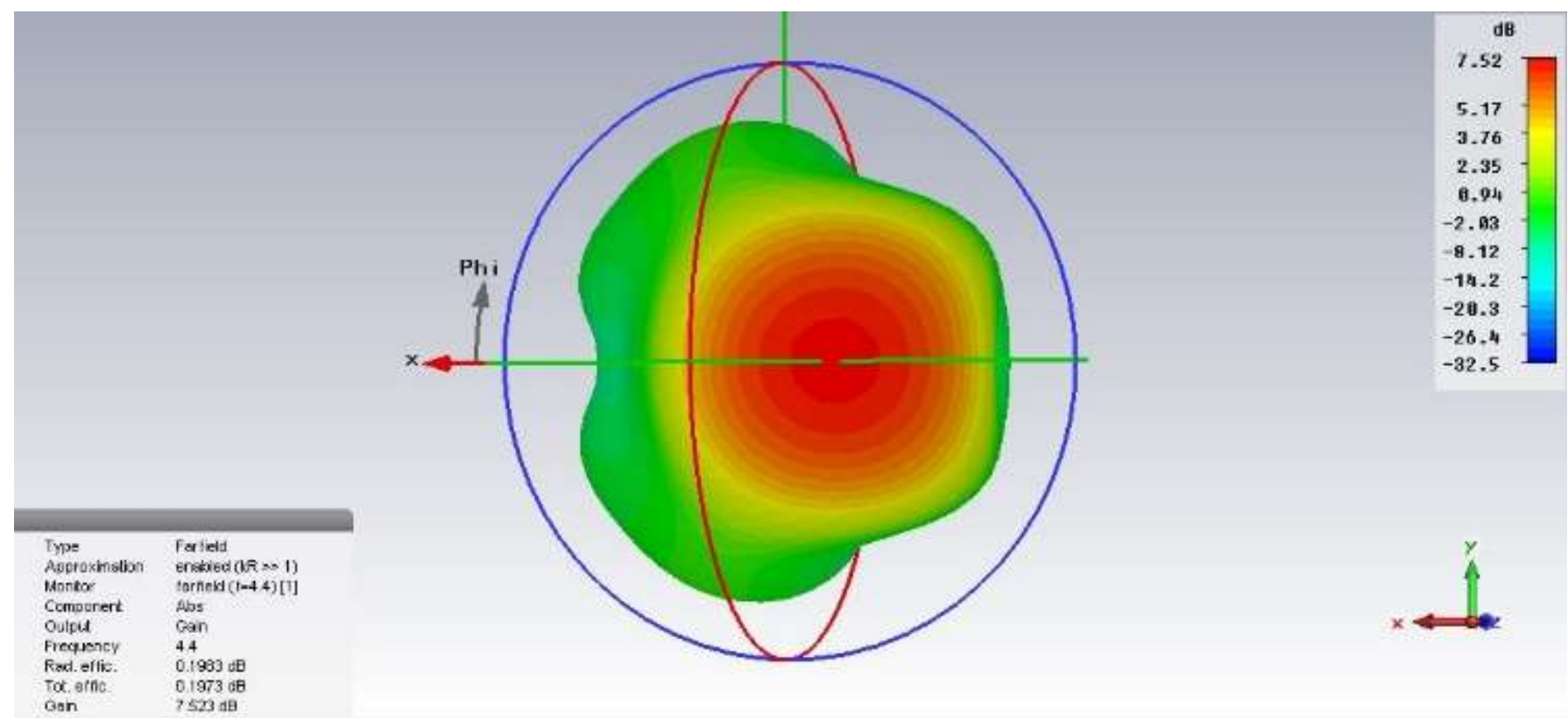

Fig -6: Gain of the proposed antenna at $4.4 \mathrm{GHz}$ 


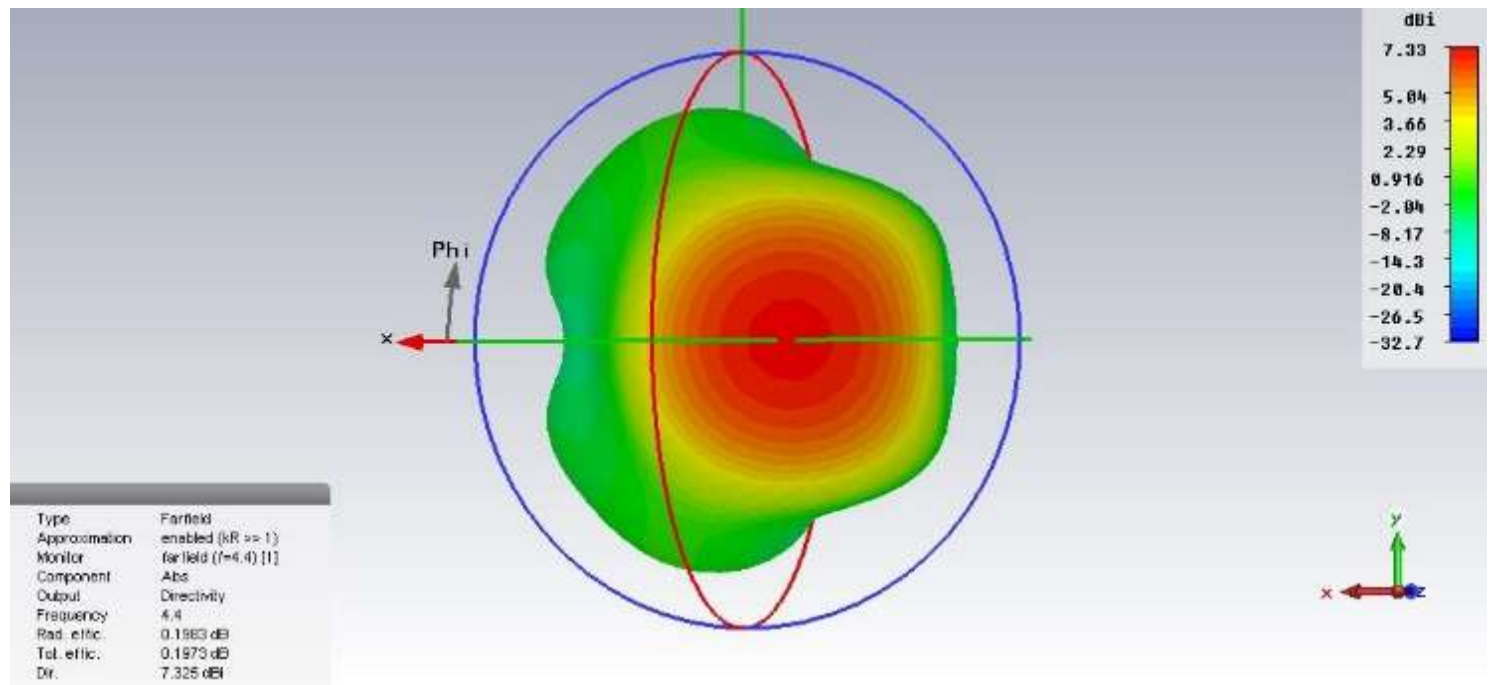

Fig -7: Directivity of the antenna at $4.4 \mathrm{GHz}$

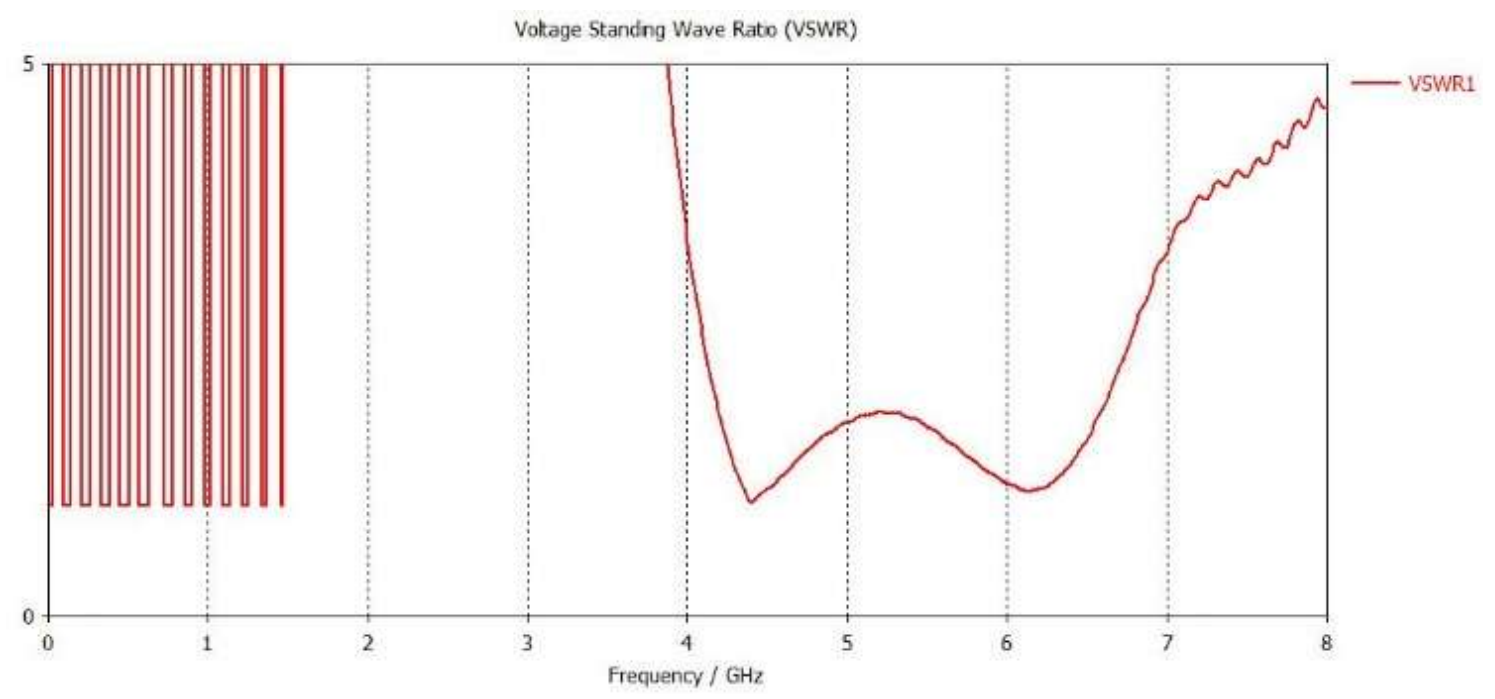

Fig -8: VSWR plot of the proposed antenna

Farfield Directivity Abs (Phi=90)

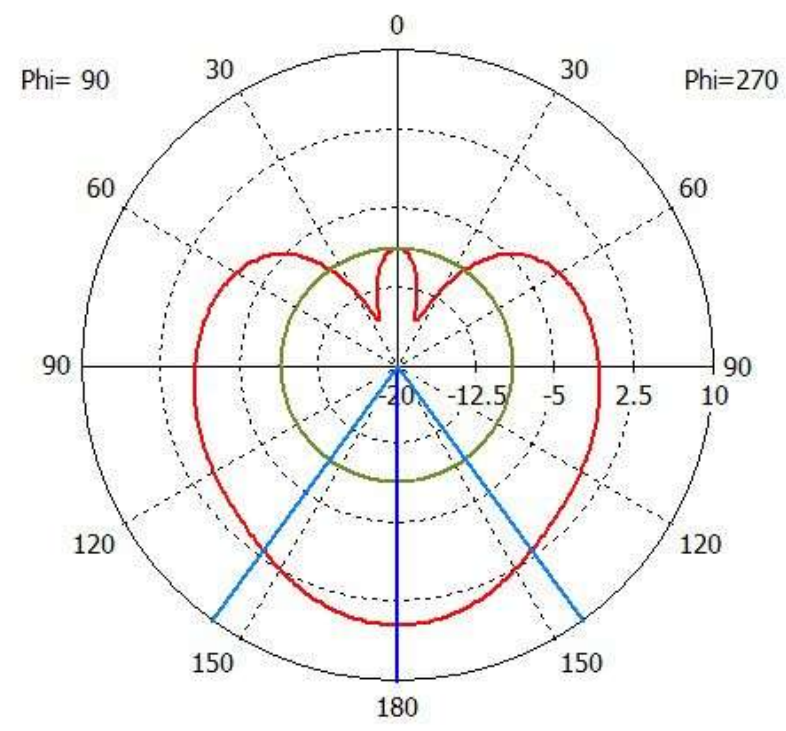

Theta / Degree vs. dBi
Frequency $=4.4$

Main lobe magnitude $=4.63 \mathrm{dBi}$ Main lobe direction $=180.0 \mathrm{deg}$. Angular width $(3 \mathrm{~dB})=72.2 \mathrm{deg}$. Side lobe level $=-13.5 \mathrm{~dB}$

Fig -9: Radiation pattern of the proposed antenna 


\section{CONCLUSION}

The microstrip patch antenna with a resonant frequency of $4.4 \mathrm{GHz}$ has been designed and proposed in this research paper. CST Microwave Studio 2014 is used to design and simulate the proposed antenna design. The proposed antenna has the impedance bandwidth of $2.43 \mathrm{GHz}(4.18 \mathrm{GHz}$ to $6.61 \mathrm{GHz}$ )which can be used for space to earth fixed satellite communications, defence systems and other many applications.

\section{ACKNOWLEDGEMENT}

We would like to thank Prof. Ekambir Sidhu, Assistant Professor, Department of Electronics and Communication Engineering, Punjabi University, Patiala for his support, guidance, assistance and supervision for successful completion this research work.

\section{REFERENCES}

[1] Balanis C.A., "Antenna Theory Analysis and Design," John Wiley \& Sons, 2005.

[2] BahiU.and BhartiaP., "Microstrip Antennas, "Artech House, Norwood, 1980.

[3] ChenZ.N and Chia M.Y.W.,"Broad band Planar Antennas: Design and Application, "John Wiley \& , 2002.

[4] RituGoyal, Y.K.Jain, "Compact Bow Shape Microstrip Patch Antenna with Different Substrates", Proceedings of IEEE Conference on Information and Communication Technologies (ICT),6505(1),pp.19,2013.doi: 10.1109/CICT.2013.6558063

[ 5] C.A.Balanis, "Antenna Theory Analysis and Design", 2nd Edition John Wiley \& Sons, NewYork, 1996.

[6] Vijay Sharma, V.K.Saxena, K.B.Sharma and D.Bhatnagar, "Radiation performance of an elliptical patch antenna with three orthogonal sectors lots," Romanian Journal of Information Science and Technology, vol.14, No.2,pp.123-130,2011.

[ 7] Tong,K.-F.,K.-M.Luk,K.-F.Lee,andR.Q.Lee,"Abroadband U-slot rectangular patch antenna onamicrowave substrate", IEEE Trans. Antennas Propagation., vol.48, pp.954-960, Jun.2000 doi: $10.1109 / 8.865229$

[ 8] Sze,J.-Y.andK.-L.Wong,"Bandwidth enhancement of amicro strip line-fed printed wides lotantenna", IEEETrans. Antennas Propagation.,vol.49, pp.10201024, July2001.

doi: $10.1109 / 8.933480$

[9] D. Bhardwaj,D. Bhatnagar,S.Sancheti,andB.Soni, Designofsquarepatch antenna with an otchonFR4 substrate, IET Microwave Antennas Propagation. 2,880-885,2008.

[10] Roopan, Raveena Bhatoa, Ekambir Sidhu, "High Gain Stacked Micostrip Folded Dipole Yagi Antenna Configurtion for WiMAX applications, "IEEE International Conference on Wireless Communication, Signal Processing and Networking (WiSPNET), IEEE Proceeding, 2016.

[11] Amarveer Singh, Ekambir Sidhu,"Novel Microstrip Patch Antenna Design for Bluetooth, IMT, WLA N and WiMAX applications, "American Journal of Engineering Research (AJER), vol.03, Issue8, pp.162170, 2014.

[12] www.docstoc.com

[13] Isha Puri,"Bandwidth and Gain increment of microstrip patch Antenna with Shifted Elliptical Slot", International Journal of Engineering Science and Technology (IJEST),vol.3,Number.7,July,2011.

\section{BIOGRAPHIES}

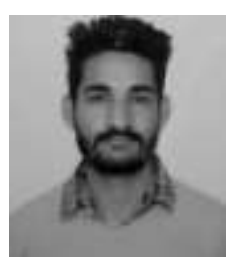

Jaspreet Singh is a student of Department of Electronics and communication Engineering, Punjabi University, Patiala, India. He is pursuing Master of Technology in the field of Electronics and Communication Engineering from Punjabi University. His areas of technical interest areAntenna Systemand Energy Harvesting System. He is a student member of Institute of Electrical and Electronics Engineers (IEEE) and member of American Society of Mechanical Engineers (ASME).

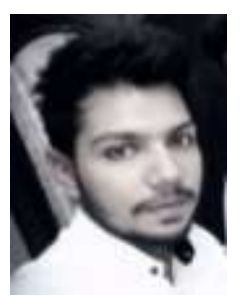

Gurnoor Singh Brar is a student of Department of Electronics and communication Engineering, Thapar Polytechnic College Patiala, India. He is pursuing Diploma in field of Electronics and Communication from Thapar Polytechnic College. His main areas of interest are Antenna, Embedded System and Energy Harvesting.

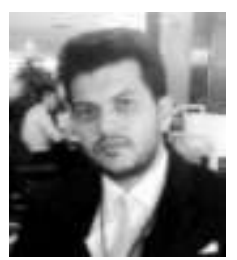

Mr. Ekambir Sidhu is an Assistant Professor at Department of Electronics and Communication Engineering Punjabi University, Patiala since September 2012. His areas of specialization are Antenna Systems and Energy Harvesting Systems. $\mathrm{He}$ is an Associate Member (AM) of Institute of Electronics and Telecommunication Engineers (IETE) and member of Institute of Electrical and Electronics Engineers (IEEE). He has research publications in the field of Microwave Antennas, Optical Antennas, Energy Harvesting Systems, Embedded Systems and Wearable Electronics. 